\section{Processo da implantação da política de medicamentos genéricos no Brasil}

\author{
Generic drug policy implementation in Brazil
}

\section{Abstract}

1 Faculdade de Saúde Pública, Universidade de São Paulo, São Paulo, Brasil.

Correspondência N. S. Romano-Lieber Departamento de Prática de Saúde Pública, Faculdade de Saúde Pública, Universidade de São Paulo. Av. Dr. Arnaldo 715, São Paulo, SP 01246-904, Brasil. nicolina@usp.br
A generic drug policy has been implemented in Brazil since 1999. Several political and administrative stages transpired between enactment of the legislation and the actual marketing and consumption of these drugs. This article describes the policy implementation process and examines the country's generic drug legislation, approved from 1999 to 2002. To contextualize these measures, the study compares articles published by two national periodicals and interviews with a government representative involved in drafting the legislation and a representative from the pharmaceutical industry. Generic drugs quickly gained considerable space in the Brazilian pharmaceutical market. Ongoing adaptation of the legislation, media support, and the government's involvement in spreading the policy were key success factors. The population's access to medicines did not increase significantly, but people can now purchase medicines at more affordable prices and with quality assurance and interchangeability.

Generic Drugs; Health Legislation; Comunications Media
Cláudia Regina Cilento Dias ${ }^{1}$ Nicolina Silvana Romano-Lieber 1

\section{Introdução}

No Brasil, é responsabilidade do Estado a formulação e execução de políticas econômicas e sociais que visem, entre outros, estabelecer condições que assegurem acesso universal às ações e serviços para promoção, proteção e recuperação da saúde 1 . Neste contexto, inserese a política nacional de medicamentos, cujo propósito é garantir o acesso da população aos medicamentos considerados essenciais, bem como a sua necessária segurança, eficácia e qualidade 2 .

Dentre as estratégias para a promoção do acesso a medicamentos, encontra-se a política de medicamentos genéricos, que são, em geral, mais baratos que os medicamentos inovadores devido em grande parte ao fato de não recaírem sobre o genérico os custos relativos ao desenvolvimento da nova molécula e dos estudos clínicos necessários. Outro fator que contribui para um custo mais baixo é o menor investimento em propaganda para tornar a marca conhecida. Os medicamentos genéricos são medicamentos similares a um produto de referência ou inovador, que pretende ser com este intercambiável, geralmente produzido após a expiração ou renúncia da proteção patentária ou de outros direitos de exclusividade, comprovada a sua eficácia, segurança e qualidade 3 .

O mercado farmacêutico brasileiro possui algumas particularidades que auxiliam a com- 
preensão do processo de implantação de medicamentos genéricos. Ele é um dos maiores do mundo, ocupa a oitava posição com vendas que atingiram, em 2003, 5,6 bilhões de dólares/ano. Neste mesmo ano, o setor exportou 280 milhões de dólares e gerou aproximadamente 47 mil empregos diretos. No Brasil, o setor é constituído por 541 empresas entre produtores de medicamentos, indústrias farmoquímicas e importadores, e apenas 29 estavam produzindo genéricos em dezembro de 20024 .

Embora expressivo, o consumo de medicamentos, no Brasil, é desequilibrado. Segundo o Ministério da Saúde, 15\% da população consomem $48 \%$ da produção de medicamentos do país e $51 \%$ consomem apenas $16 \%$ do mercado, mas somente $40 \%$ da população pode adquirir medicamentos 2 .

Entre outras questões, as dificuldades recorrentes de acesso ao medicamento pela população propiciaram, em 1999, uma Comissão Parlamentar de Inquérito (CPI) no Congresso Nacional enfocada na indústria farmacêutica e no embate do governo para a redução de preços no setor. Muito embora o movimento dos genéricos tenha como marco a Portaria $n .3 .916^{2}$ de 30 de outubro de 1998, o inquérito prestouse como um dos deflagradores do processo de implantação, visto que política de medicamentos genéricos é internacionalmente reconhecida como um mecanismo de redução de preços de medicamentos.

A Portaria $n .3 .916^{2}$ apresentou como um dos objetivos a promoção do uso de medicamentos genéricos e determinou que o gestor federal devesse identificar os mecanismos necessários para atingir essa finalidade. Três meses após a sua publicação, ocorreu a publicação da Lei $n .9 .787$ 3, em 10 de fevereiro de 1999, alterando a Lei $n .6 .360$ e instituindo a Política de Medicamentos Genéricos. Com isso, foram traçadas as diretrizes, normas e critérios para sua implantação, revogando o Decreto n. 793/93.

\section{Configuração do problema, objetivos e métodos}

Entre a promulgação da Lei e a efetiva comercialização e consumo de medicamentos genéricos no país, sucederam-se diversas etapas no âmbito político e administrativo. O objetivo deste trabalho é descrever este processo havido na época. Para tanto, foram examinadas as Leis, Decretos e Resoluções, publicadas no período compreendido entre 1999 e 2002, relativos aos medicamentos genéricos no Brasil. Para melhor contextuar tais medidas, foram confrontadas as notícias publicadas em dois perió- dicos de cobertura nacional no mesmo período com entrevistas concedidas por um representante do governo, envolvido com a elaboração da legislação brasileira de medicamentos, e um representante da indústria farmacêutica. As entrevistas, obtidas no segundo semestre de 2002, foram gravadas com a permissão dos entrevistados e as questões buscaram esclarecer o quadro político e conjuntural que envolveu a elaboração da legislação de genéricos. Os jornais escolhidos foram Folha de S. Paulo e O Estado de São Paulo. Trabalho anterior listou as páginas da $w e b$ consultadas na época 5 .

Atendendo aos aspectos éticos, o projeto foi aprovado pelo Comitê de Ética em Pesquisa da Faculdade de Saúde Pública, Universidade de São Paulo.

\section{Resultados e discussão}

\section{Panorama conjuntural}

De acordo com o representante do governo, a implantação dos genéricos não foi premeditada. Segundo o mesmo, o então Ministro da Saúde solicitou que fossem avaliados projetos de lei de interesse da área da saúde no Congresso Nacional aguardando tramitação. O projeto de lei dos genéricos destacava-se, pois era uma antiga reivindicação do setor. Para o representante da indústria farmacêutica, todavia, o apelo político que os genéricos representavam foi um fator fundamental para a decisão tomada, visto que $o$ fato foi considerado como uma marca de ação do então ministro da saúde.

A regulamentação técnica para registro dos medicamentos genéricos foi formalizada seis meses após a publicação da Lei $n .9 .7873$. Com a Resolução $n$. 3916 de 9 de agosto de 1999, foram estabelecidas as condições de registro, fabricação, controle de qualidade, testes, prescrição e dispensação. Embora a complexidade do assunto requeresse a formação de equipe capacitada, o governo foi alvo de críticas no tocante à demora na sua elaboração. Para o representante do governo, não podia ter sido diferente, já que "Tínhamos que aprender, foi muito difícil aprender, (...) e debaixo do tiroteio da CPI de medicamentos e do destaque do tema não podíamos fazer menos de 100\%" 5 (p. 39).

Os primeiros genéricos foram registrados quase seis meses depois da publicação da $R e$ solução $n$. 391, conforme a Resolução $n .747$ de 2 de fevereiro de 2000. Esse tempo foi considerado razoável pelo representante da indústria farmacêutica, segundo o qual as validações de produção e de análise, além dos testes de equi- 
valência farmacêutica, demandam um período de tempo muito próximo a este.

A indústria farmacêutica reagiu à implantação dos genéricos. Logo após a publicação da Resolução n. 391, enquanto ainda não haviam sido lançados medicamentos desse tipo, a mídia impressa denunciava o encaminhamento de comunicado da Associação Brasileira da Indústria Farmacêutica (ABIFARMA) aos médicos e às farmácias. No comunicado, afirmava-se que o "farmacêutico não pode, em nenhuma circunstância, substituir prescrições, sob pena de crime hediondo" 5 (p. 40). A mesma notícia informava que o comunicado gerou protestos do Conselho Federal de Farmácia e da Associação dos Laboratórios Farmacêuticos Nacionais (ALANAC). Tal reação não se deu sem motivo. Aparentemente, entre a publicação da resolução e o início da comercialização dos genéricos, muitas farmácias estavam substituindo os medicamentos de referência por medicamentos similares com ou sem marca. A indústria farmacêutica denunciou o acontecimento e lançou uma campanha publicitária de esclarecimento sobre a "substituição indevida de remédios nas farmácias" 5 (p. 41).

Outra reação da indústria farmacêutica foi fornecer carimbos, etiquetas e receituários já impressos aos médicos com frases de conteúdo similar a "Não substituir por genéricos" 5 (p. 43). A Agência Nacional de Vigilância Sanitária (ANVISA), instituição responsável pelas regulações de políticas como a dos medicamentos genéricos, reagiu com a republicação da $R e$ solução n. 391, em 19 de novembro de 1999, na qual incluiu a proibição explícita desta prática, além de exigir "de próprio punho" do prescritor qualquer restrição ao intercambiamento.

A indústria farmacêutica não assumiu publicamente uma postura contrária aos genéricos, afirmando que a ABIFARMA era, na verdade, contra os "falsos genéricos" 5 (p. 44). Conforme o representante da indústria farmacêutica, a indústria era contrária a uma situação em que não havia garantia da qualidade dos medicamentos.

A resistência aos medicamentos genéricos também foi evidenciada entre prescritores. Pesquisa realizada pela ANVISA 8, na época da implantação, mostrou que $80 \%$ das receitas avaliadas eram de medicamentos de marca, ainda que $78 \%$ dos médicos se manifestassem de forma positiva sobre a qualidade dos genéricos. $\mathrm{O}$ resultado permite supor uma possível falta de hábito entre estes, indicando a necessidade de ações contínuas de incentivo à prescrição pelo nome genérico, inclusive na formação dos futuros profissionais. As ações dirigidas aos mé- dicos se mostravam cruciais, tendo em vista que, em $71 \%$ dos casos examinados, os consumidores compraram o medicamento na forma prescrita.

Na França, estudo comparativo de políticas que buscavam compreender a pouca penetração dos genéricos no mercado, mostrou que o ponto chave era a ausência de estímulos à prescrição e à dispensação de genéricos naquele país 9 . Da mesma forma, Anis 10 relata que, no Canadá, exame das várias políticas para substituição revelou que receituários padronizados e decurso de tempo não foram significativos para se alterar o padrão de prescrição. Foram fatores determinantes os constrangimentos legais, a observação de listas obrigatórias de referência e os esquemas de deduções ou co-pagamento dos gastos com medicamentos, além do envolvimento dos consumidores.

Outros estudos destacam a necessidade de pesquisar as práticas locais de prescrição e consumo antes de propor medidas de intervenção. Vários fatores influenciam o resultado, como o canal de disseminação, o conteúdo da mensagem, a forma e a pessoa envolvida 11 . Saxenian 12 destaca, além desses fatores, a lealdade à marca, que seria maior em países em desenvolvimento que em países desenvolvidos porque (1) as empresas de medicamentos de marca fornecem a maior parte das informações e (2) o controle de qualidade do governo, naqueles países, tenderia a ser pouco confiável.

\section{Regulamentações adicionais para atendimento da demanda de genéricos}

Aparentemente, a implantação dos medicamentos genéricos no Brasil também sofreu resistência por parte do comércio farmacêutico. A mídia impressa, em dezembro de 2001, discutia esse tema e comentava que, para esse segmento, não havia atrativo em vender genéricos. No mesmo artigo, argumentava-se que as grandes redes de farmácias e drogarias aderiram aos genéricos, pois seus preços mais baixos atrairiam compradores que consumiriam outros produtos de higiene ou beleza, com os quais poderiam recompor suas "margens de lucro". As pequenas farmácias, entretanto, não possuíam capital de giro suficiente para investir em produtos paralelos. Diante da resistência das farmácias em comercializar genéricos, o ministro da saúde ameaçou "enquadrar" as farmácias, forçando-as a vender os medicamentos genéricos 5 .

A falta de genéricos nas farmácias originava todo tipo de teoria conspiratória. A mídia impressa em 17 de julho de 2000 dava idéia da situação, sugerindo boicote das farmácias, de- 
vido à ausência do lucro, ou distribuidoras associadas a indústrias multinacionais para impedir a venda de genéricos, ou mesmo médicos que estariam sendo pressionados pelos laboratórios estrangeiros para não receitá-los 5 . É possível, todavia, que nem as farmácias nem os fabricantes estivessem preparados para atender à demanda inicial por genéricos, como veio a se evidenciar pelos fatos subseqüentes.

Na tentativa de regularizar a oferta, sucessivas medidas foram sendo tomadas pelo governo para regulação do mercado a cada novo problema observado. Assim, a primeira medida foi a publicação da Resolução $n .45$ 13, em 15 de maio de 2000, tornando obrigatória a afixação da relação de medicamentos genéricos registrados na ANVISA nas farmácias e drogarias "em local de fácil acesso e visibilidade". Posteriormente, essa resolução foi revogada pela $R e$ solução n. 99 14, de 22 de novembro 2000. Nesta, estendia-se o prazo até o 15o dia do mês seguinte para que a listagem fosse atualizada. Conforme o representante do governo, o propósito da Resolução era melhor informar ao público consumidor. O resultado da medida foi questionável, dado que a pesquisa realizada pela ANVISA mostrou que somente $7,2 \%$ dos consumidores chegaram a consultar a lista de genéricos nas farmácias ou drogarias 8 .

Rapidamente se avaliou que a colocação da lista de genéricos registrados não era suficiente para normalizar a distribuição, sendo necessário o controle do que era produzido, importado, bem como o local de comercialização para que se pudessem conhecer os pontos falhos e intervir. Além disso, deixou-se de considerar que nem todos os medicamentos registrados são comercializados, pois, com freqüência, a indústria posterga ou desiste do lançamento de um medicamento. Dessa forma, 2,5 meses após a publicação da Resolução $n$. 45, foi publicada a Resolução $n .78$ 15, em 21 de agosto de 2000, obrigando as empresas importadoras e produtoras de genéricos a entregarem o balanço mensal de vendas. Deveriam ser informados a quantidade produzida, a capacidade instalada, o total de lotes fabricados, a quantidade de produto vendido, o local para onde o lote foi vendido, além de dados sobre o tamanho e participação do mercado. De acordo com o representante do governo, o propósito dessa medida era fornecer à ANVISA o acesso aos dados das movimentações das empresas.

Os balanços começaram a ser recebidos a partir de 10 de setembro 2000, e a Resolução determinava que as empresas enviassem também balanços retroativos dos meses de junho e julho de 2000. Com o recebimento dos dados, avaliou-se que o déficit entre a demanda e a produção não seria resolvido em curto prazo, porque o aumento da produção não é um processo rápido. Diante desse fato e da necessidade premente de se ter mais genéricos disponíveis, o governo tomou uma decisão controversa, publicando o Decreto n. 3.675 16, em 28 de novembro de 2000 . No decreto, foi permitido o registro por um ano, por meio de um processo simplificado e com trâmite acelerado dentro da ANVISA, de medicamentos genéricos que já fossem registrados no Canadá, Europa e Estados Unidos.

Este processo particular de registro teria um procedimento diferente do convencional. A documentação a ser apresentada seria simplificada e não haveria necessidade de serem apresentados testes comprobatórios da bioequivalência e equivalência farmacêutica contra o medicamento-referência nacional no ato do registro. Tais testes deveriam ser apresentados em até um ano após a concessão do registro. Em contrapartida, a empresa, obrigatoriamente, colocaria o produto no mercado em até 45 dias após a concessão do registro, sob pena de sua perda compulsória. A esse respeito, o então ministro da saúde fez declarações, esclarecendo que o motivo da criação do registro especial era facilitar a importação de genéricos 5 . O caráter circunstancial da medida foi enfatizado pelo representante do governo. Para ele: "Naquele momento, foi um mal necessário. Foi uma tentativa de aumentar o número de genéricos no mercado de maneira mais rápida e tivemos que correr riscos" 5 (p. 54).

As indústrias nacionais protestaram porque o decreto tratava os produtos importados de forma diferenciada, uma vez que, num primeiro momento, eles não seriam submetidos ao teste de bioequivalência. Para o representante da indústria farmacêutica o decreto foi " $u m$ absurdo" 5 (p. 55), pois havia um procedimento regulamentar a ser seguido pelos laboratórios locais e um procedimento mais facilitado aos estrangeiros. Acrescentou, ainda, que o Brasil não criou mecanismos de proteção à indústria nacional, na medida em que permitiu a entrada de genéricos de outros países sem algumas exigências de reciprocidade lá existentes.

O decreto em pauta, além de fonte de muitas críticas, apresentava sério problema técnico, dado que, em sua primeira versão, não exigia nenhum teste comprobatório de equivalência farmacêutica. Por mais que o produto possuísse o estudo de bioequivalência contra um medicamento de empresa diferente da detentora do produto de referência nacional. Rapidamente, publicou-se o Decreto n. 3.718 17, em 
4 de janeiro de 2001, corrigindo a distorção. Passou-se a exigir, caso o medicamento de referência utilizado no ensaio de bioequivalência não fosse da mesma empresa do medicamento de referência nacional, o certificado de equivalência farmacêutica e o estudo comparativo dos perfis de dissolução entre o medicamento genérico e a referência nacional.

Entretanto, apesar dessa facilidade para o registro de produtos importados, a medida não surtiu o efeito esperado, tendo havido apenas um registro por meio do trâmite especial. As empresas importadoras continuaram protocolando pedidos por meio do registro normal. $\mathrm{O}$ fato explica-se, pois, com o registro realizado pela forma especial, a empresa teria ainda que apresentar obrigatoriamente novo estudo de bioequivalência contra o produto de referência nacional ao término de um ano, sendo este um ensaio dispendioso. Caso o registro fosse solicitado pelo regime normal, seriam necessários apenas os ensaios de equivalência farmacêutica e o perfil de dissolução comparativa, testes mais baratos que aquele. Um novo estudo de bioequivalência seria exigido apenas no caso do estudo apresentado não cumprir com o requerido pela legislação vigente.

Seis meses mais tarde, a ANVISA publicou o Decreto $n$. 3.84118 permitindo ao estudo de bioequivalência de produtos importados o mesmo tratamento daqueles que entrassem por meio do regime normal. Com isso, não seria mais necessário repetir-se obrigatoriamente o teste contra o produto de referência nacional. Assim, foram publicados 96 registros, divididos em 72 fármacos. Estes registros representaram 16,6\% do total de 578 registros de medicamentos genéricos aprovados até outubro de 2002.

Esses dados mostram que o registro especial contribuiu para disponibilizar medicamentos genéricos nas farmácias. Ressalte-se, todavia, que, dos 48 produtos que obtiveram esse tipo de registro, no período de dezembro de 2000 a fevereiro de 2002, apenas 34 tiveram a transição publicada. As hipóteses para que isso tenha ocorrido são as avaliações negativas do mercado pela empresa ou, mais preocupante, sua impossibilidade de comprovar os itens da qualidade e/ou bioequivalência com o produto de referência. Na entrevista, o representante do governo admitiu que houve casos em que não foi possível a transição. A ANVISA não publicou os indeferimentos dos pedidos de transição de registro especial, conforme procedimento padrão, deixando, simplesmente, que o prazo do registro expirasse.

O prazo para concessão de registro especial foi estendido até 28 de novembro de 2002 por meio do Decreto n. 3.960 19, de 11 de outubro de 2001. A última publicação relacionada ao registro especial foi o Decreto n. 4.20420 de 24 e abril de 2002, restringindo sua concessão apenas para genéricos inéditos.

A prática do registro especial de medicamentos genéricos já havia sido cogitada em trabalho financiado pelo Banco Mundial em 1994. Nesse estudo, voltado às recomendações para que se reduzissem as despesas com medicamentos, sugere-se, entre outras medidas, que os testes de bioequivalência realizados em outros países sejam aceitos quando não houver condições locais para fazê-los. Essa prática, embora possa restringir o âmbito competitivo, favorecendo drogas mais caras, poderia justificar-se em termos de custo benefício. Medidas temporárias também são preconizadas, como por exemplo, a importação de medicamentos registrados em países de regulação mais restritiva. Dessa forma, seria possível o acesso a produtos de qualidade, mesmo nos países com agências reguladoras ainda não totalmente constituídas 12 .

\section{Regulamentações adicionais para condicionamento da oferta}

Embora a Lei $n .9 .7873$ estabelecesse que os medicamentos similares deveriam sempre ser identificados por nome comercial ou marca e concedesse o prazo de seis meses para os similares com e sem marca adaptarem-se e procederem às alterações necessárias, publicou-se uma regulamentação específica para esse fim. Isto porque, para cumprir a Lei e continuar vendendo pelo nome do princípio ativo, muitas empresas adotaram apenas o nome da empresa junto ao nome do princípio ativo como marca comercial. No dia 24 de outubro de 2000 , publicou-se a Resolução $n .9221$ que determinava o prazo de seis meses para encerrar a fabricação dos similares sem marca, prazo que se encerrou em 23 de novembro de 2001. De forma complementar, em 16 de março de 2001, foi publicada a Resolução $n .36$ 22, proibindo a comercialização de medicamentos registrados com denominação genérica e dando prazo de 180 dias para seu cumprimento.

Percebeu-se, também, a necessidade de se criar uma identidade visual diferenciada para esses medicamentos, de modo a facilitar a identificação pelo consumidor e a distinção entre medicamento genérico e medicamento similar. Em paralelo ao fim da comercialização de medicamentos similares sem marca, a ANVISA preparava o lançamento de um logotipo para os genéricos. Para o representante do governo, 
a identidade visual permitiria que o "consumidor identificasse o genérico na prateleira, que soubesse o que estava comprando e não fosse enganado pelo vendedor. Como no Brasil a assistência farmacêutica é deficiente, o motor desta transformação no mercado brasileiro foi o comprador de remédio" 5 (p. 61). Nesse aspecto, houve participação da indústria. Segundo seu representante, produtores de genéricos observaram que o consumidor poderia confundirse, se não fosse criado um identificador. Com a publicação da Resolução $n .4723$ em 05 de abril de 2001, tornou-se obrigatória a inclusão do logotipo dos genéricos nas embalagens externas. O conjunto destas resoluções entrou em vigor na mesma época. Assim, o fim da comercialização dos similares sem marca se deu em 15 de setembro de 2001 e o logotipo do genérico entrou em vigor em 5 de outubro daquele ano. A estratégia de adotar identidade visual diferenciada para os genéricos atingiu os resultados esperados, pois pesquisa da ANVISA revelou que $71 \%$ dos consumidores sabiam reconhecer um genérico, sendo $55 \%$ pelo logotipo da embalagem 8 .

\section{O processo comunicativo na implantação dos medicamentos genéricos}

Destaca-se o importante papel da divulgação dos medicamentos genéricos para sua aceitação. Houve empenho pessoal do ministro da saúde bem como de membros da ANVISA nos diversos canais de comunicação. Divulgou-se o produto em congressos médicos e associações de consumidores. Houve presença pública freqüente para prestar esclarecimentos, denunciar os entraves nas indústrias e nas farmácias à causa dos genéricos, mobilizando a opinião pública. Também a imprensa exerceu papel fundamental, pois colocou a opinião pública a favor dos genéricos, divulgou os problemas, a resistência dos diversos setores, cobrou o governo e exigiu a disponibilidade dos genéricos nas farmácias.

A efetivação da estratégia governamental foi avaliada em pesquisa da ANVISA. Em 2001, foi conduzida pesquisa entre balconistas de farmácia, relativa ao perfil do consumidor de genéricos 8 . Dentre os resultados, destaca-se que $58 \%$ dos consumidores sabiam da existência daqueles medicamentos e $23 \%$ os recusavam. Ainda, $41 \%$ insistiam em comprar genéricos e $40 \%$ pediam que se trocasse o medicamento de referência receitado pelo genérico.

Outra pesquisa, também realizada pela ANVISA em 2001 entre consumidores 8, mostrou que $82 \%$ já haviam visto propaganda/cam- panha de esclarecimento sobre medicamentos genéricos. Também indicou que $95 \%$ dos entrevistados declararam conhecê-los e $91 \%$ os definiram corretamente; $80 \%$ acreditavam que faziam o mesmo efeito dos medicamentos de referência e $71 \%$ concordavam que o genérico tinha preço mais baixo. Entretanto, apesar de conhecerem o produto e nele confiarem, apenas $48 \%$ pediam medicamentos genéricos, indicando falta de ações para promover a lembrança do genérico no consumidor, tanto no momento de aquisição do medicamento, como no instante da prescrição.

Os novos meios de informação mudaram as expectativas das pessoas em relação ao controle sobre os cuidados à saúde. Segundo Glatter 24, o papel da mídia na questão dos medicamentos tem gerado controvérsia desde a liberação de promoção de medicamentos sob receita em veículos de massa (jornais, revistas, rádio e TV), pelo Food and Drug Administration (FDA), agência reguladora desses produtos nos Estados Unidos. Nessa linha, Saxenian 12 relata que, países em desenvolvimento intermediário, podem atingir consumidores por meio de programas de educação veiculados pela mídia de massa, mas ressalta que a transformação das práticas apenas pela educação é insuficiente, e a combinação da educação com estímulos financeiros funciona melhor. De acordo com Glatter 24 , muito além do "direito de saber", como propõe a indústria farmacêutica ao promover seus produtos, as pessoas também têm direito a informações relativas às suas necessidades, como a disponibilidade de genéricos e de outros tratamentos alternativos. O papel positivo da mídia foi confirmado também na Espanha. Uma pesquisa feita três anos após a introdução de medicamentos genéricos neste país mostrou que $60 \%$ dos pesquisados em atendimento primário conheciam o produto, e a mídia tinha sido o principal veículo de informação para $78,4 \%$ deles 25 .

Aparentemente, houve acerto na escolha dos diferentes instrumentos, visto que se sabe que o êxito no uso de recursos de mídia decorre da compatibilização local. Estratégias de sucesso para aumentar o conhecimento sobre os medicamentos essenciais e genéricos e a confiança neles foram utilizadas entre os países africanos de fala francesa em 1995. Houve promoção de concurso de frases, cartazes, músicas e apresentações. A ampla participação, em 22 países, resultou além de material para divulgação em linguagem popular, também um melhor entendimento dos conceitos locais sobre medicamento e cura 26. 
Efeitos dos quatro primeiros anos de vigência de medicamentos genéricos no Brasil

A criação dos medicamentos genéricos trouxe exigências que até então eram desconsideradas, como, por exemplo, as validações de limpeza, de produção e dos métodos analíticos. Os quesitos relativos ao princípio ativo e à equivalência da ação biológica tornaram necessário o monitoramento da qualidade, de forma a garantir a bioequivalência nos lotes de produção segundo os padrões oferecidos no ato do registro.

O impacto da regulamentação dos genéricos alcançou também os demais procedimentos de registro. A nova legislação para os medicamentos similares e novos, por exemplo, passou a ter os mesmos requerimentos de qualidade exigidos para os genéricos 27 .

O crescimento das vendas de medicamentos genéricos nos primeiros 18 meses de sua introdução no mercado foi em torno de $15 \%$ ao mês. Entre junho de 2000 e agosto de 2001, a venda de genéricos cresceu $249,42 \%$, chegando a 7,06 milhões de unidades 28. Desde a Resolução $n .74$ de 2 de fevereiro de 2000, o número de genéricos registrados e comercializados tem crescido. Em abril de 2004 os medicamentos genéricos totalizavam 1.124 medicamentos registrados, divididos em 270 fármacos, 57 classes terapêuticas e já atendiam a $60 \%$ da necessidade de prescrição 29.

Conseqüentemente, o perfil de consumo de medicamentos no mercado brasileiro alterouse. Segundo o IMS Health, empresa dedicada ao acompanhamento do mercado farmacêutico global, entre dezembro de 2000 e novembro de 2002, ocorreu uma rápida e grande evolução na participação dos genéricos no mercado brasileiro, um pequeno declínio das vendas dos medicamentos de referência e uma forte queda nas vendas de medicamentos similares. A ANVISA também verificou evolução da participação da quantidade vendida de medicamentos genéri$\cos 28$. Nos primeiros anos da implantação dos genéricos, a mídia impressa, acompanhando as transformações, noticiava que os remédios de marca estavam vendendo menos 5 . Cálculos de algumas multinacionais indicavam uma queda de até $30 \%$ na venda dos produtos de referência em dezembro de 20025 . Além disso, outra pesquisa por amostragem feita pela ANVISA 8 mostrou que a comercialização não havia crescido em volume em $47 \%$ das farmácias pesqui- sadas, sugerindo a simples migração do mesmo consumidor do medicamento de marca para o genérico.

Os resultados comerciais refletiram as diferentes ações para agilizar o processo de registro e o genérico já cobria 9,9\% das vendas no mercado, mostrando o padrão de aceitação 30 . Esses números mostram-se superiores ao de alguns países onde existem genéricos há muitos anos, como França (2\%), Itália (1\%), Espanha (1\%) e Portugal (1\%), alcançando o Japão (8\%) e a Áustria (6\%). Contudo, estão distantes ainda de países como a Grã-Bretanha (65\%), Dinamarca (60\%), Estados Unidos (49\%), Canadá (40\%) e Alemanha (38\%) 31 .

\section{Conclusões}

O uso adequado dos recursos da mídia mostrou-se fundamental para a implantação da política de medicamentos genéricos no país.

No esforço do governo para viabilizar esta nova política, cabe destaque para as sucessivas correções, sem as quais, dificilmente os genéricos estariam implantados. A legislação pertinente foi modificada várias vezes, frente às necessidades e às situações inesperadas que surgiram durante o processo. Guardadas as proporções, foi um atendimento das recomendações expressas pela OMS, ao preconizar a necessidade de acompanhamento e correção de rumos na implantação efetiva de uma política nacional de medicamentos 30 .

O Brasil atingiu em poucos anos um patamar de vendas de genéricos que outros países demoraram várias décadas para alcançar. $\mathrm{O}$ sucesso na implantação dessa política pode ser atribuído a vários fatores, como a contínua adequação da legislação e o respaldo da mídia que proporcionou ao governo o apoio popular.

A implantação da política de genéricos no país, embora não tenha favorecido um aumento significativo de acesso aos medicamentos na população brasileira, foi um ganho. Os consumidores passam a contar com a oportunidade de comprar medicamentos a preços mais acessíveis e com garantia de qualidade e intercambiamento.

O impacto da regulamentação dos genéricos alcançou os procedimentos de registro dos demais tipos de medicamentos, trazendo avanços na questão da qualidade destes. 


\section{Resumo}

A política de medicamentos genéricos foi estabelecida no Brasil em 1999. Entre a promulgação da Lei e a efetiva comercialização e consumo desses medicamentos, sucederam-se diversas etapas no âmbito político e administrativo. O objetivo deste trabalho foi descrever este processo ocorrido na época da implantação. Fo $i$ examinada a legislação pertinente aos medicamentos genéricos no país, publicada entre 1999 e 2002. Para contextuar tais medidas, confrontaram-se notícias publicadas em dois jornais de abrangência nacional com entrevistas de um representante do governo, envolvido na elaboração da legislação brasileira de medicamentos, e um representante da indústria farmacêutica. Em pouco tempo, os genéricos conquistaram espaço considerável no mercado farmacêutico brasileiro. A contínua adequação da legislação, o respaldo da mídia e o envolvimento do governo em sua divulgação possibilitaram o sucesso obtido. Não houve aumento significativo do acesso da população aos medicamentos, entretanto, passou-se a contar com a oportunidade de adquirir medicamentos a preços mais acessiveis e com garantia de qualidade e intercambiamento.

Medicamentos Genéricos; Legislação Sanitária; Meios de Comunicação

\section{Referências}

1. Brasil. Lei n. 8.080. Dispõe sobre as condições para a promoção, proteção e recuperação da saúde, a organização e o funcionamento dos serviços correspondentes. Diário Oficial da União 1990; 20 set.

2. Brasil. Portaria n. 3.916. Aprova a Política Nacional de Medicamentos. Diário Oficial da União 1998; 10 nov.

3. Brasil. Lei n. 9.787. Altera a Lei n. 6.360, de 23 de setembro de 1976, que dispõe sobre a vigilância sanitária, estabelece o medicamento genérico, dispõe sobre a utilização de nomes genéricos em produtos farmacêuticos e dá outras providências. Diário Oficial da União 2000; 11 fev.

4. Federação Brasileira da Indústria Farmacêutica. Indicadores da Indústria. http:/ / www.sindusfarma. org.br/index.htm (acessado em 30/Dez/2002).

5. Dias CC. Medicamentos genéricos no Brasil de 1999 a 2002: Análise da legislação, aspectos conjunturais e políticos [Dissertação de Mestrado]. São Paulo: Faculdade de Saúde Pública, Universidade de São Paulo; 2003.

6. Brasil. Resolução n. 391, de 9 de agosto de 1999. Aprova o Regulamento Técnico para Medicamentos Genéricos. Diário Oficial da União 1999; 10 ago.

7. Brasil. Resolução RE n. 74, de 2 de fevereiro de 2000. Concede autorização de funcionamento para empresas de medicamentos. Diário Oficial da União 2000; 3 fev.

8. Agência Nacional de Vigilância Sanitária. Resultado de pesquisas. http://www.anvisa.gov.br/hotsite/ genericos/index.htm (acessado em 03/Nov/2002).

\section{Colaboradores}

C. R. C. Dias contribuiu na revisão bibliográfica, trabalho de campo e na redação do artigo. N. S. Romano-Lieber colaborou na revisão bibliográfica e redação do artigo.
9. Le Pen C. L'economie des medicaments generiques. Journal d'Economie Medicale 1996; 14: 413-37.

10. Anis AH. Substitution laws, insurance coverage, and generic drug use. Med Care 1994; 32:240-56.

11. Le Grand A, Hogerzeil HV, Haaijer-Ruskamp, FM. Intervention research in rational use of drugs: a review. Health Policy Plan 1999; 14:89-102.

12. Saxenian H. Getting the most out of pharmaceutical expenditures. Human Resources Development and Operations Policy Working Papers, 37. http://www.worldbank.org/html/extdr/hnp/hdd flash/hcwp/hrwp033.html (acessado em 20/Ago/ 2005).

13. Brasil. Resolução RDC n. 45, de 15 de maio de 2000. Estabelece que todas as farmácias, drogarias e estabelecimentos que comercializem medicamentos ficam obrigados a afixar em local de fácil acesso e visibilidade, a relação dos medicamentos genéricos, registrados pela Agência Nacional de Vigilância Sanitária, nos termos da Lei n. 9.787, de 10 de fevereiro de 1999. Diário Oficial da União 2000; 16 mai.

14. Brasil. Resolução RDC n. 99, de 22 de novembro de 2000. Obriga os estabelecimentos que dispensam medicamentos, nos termos da Lei n. 5.991, de 19 de dezembro de 1973, a manter à disposição dos consumidores lista atualizada dos medicamentos genéricos, conforme relação publicada mensalmente pela Agência Nacional de Vigilância Sanitária. Diário Oficial da União 2000; 23 nov. 
15. Brasil. Resolução RDC n. 78, de 17 de agosto de 2000. Dispõe sobre a apresentação mensal de informações referentes à produção e comercialização de produtos genéricos. Diário Oficial da União 2000; 21 ago.

16. Brasil. Decreto n. 3.675 , de 28 de novembro de 2000. Dispõe sobre medidas especiais relacionadas com o registro de medicamentos genéricos, de que trata o art. 4o da Lei n. 9.787, de 10 de fevereiro de 1999. Diário Oficial da União 2000; 29 nov.

17. Brasil. Decreto n. 3.718, de 3 de janeiro de 2001. Dá nova redação a dispositivos do Anexo ao Decreto n. 3.675 , de 28 de novembro de 2000, que dispõe sobre medidas especiais relacionadas com o registro de medicamentos genéricos, de que trata o art. 4o da Lei n. 9.787, de 10 de fevereiro de 1999. Diário Oficial da União 2001; 4 jan.

18. Brasil. Decreto 3.841, de 11 de junho de 2001. Dá nova redação ao dispositivo do Decreto n. 3.675 de 28 de novembro de 2000, que dispõe sobre medidas especiais relacionadas com medicamentos genéricos, de que trata o art. 4o da Lei n. 9.787, de 10 de fevereiro de 1999. Diário Oficial da União 2001; 28 jun.

19. Brasil. Decreto n. 3.960, de 10 de outubro de 2001. Dá nova redação ao art. 1o do Decreto n. 3.675, de 28 de novembro de 2000 , que dispõe sobre medidas especiais relacionadas com o registro de medicamentos genéricos de que trata o art. 4o da Lei n. 9.787, de 10 de fevereiro de 1999. Diário Oficial da União 2001 ; 11 out.

20. Brasil. Decreto n. 4.204, de 23 de abril de 2002. Dá nova redação ao art. 1o do Decreto no 3.675, de 28 de novembro de 2000 , que dispõe sobre medidas especiais relacionadas com o registro de medicamentos genéricos de que trata o art. 4o da Lei n. 9.787, de 10 de fevereiro de 1999. Diário Oficial da União 2002; 24 abr

21. Brasil. Resolução RDC n. 92, de 23 de outubro de 2000. Modifica a Resolução ANVS n. 510, de 1o de outubro de 1999. Diário Oficial da União 2000; 24 out.

22. Brasil. Resolução RDC n. 36, de 15 de março de 2001. Proibi a comercialização dos medicamentos similares registrados com denominação genérica, exceto os definidos como de referência conforme a Resolução - RDC/ANVISA n. 32, de 9 de março de 2001, a partir de 180 (cento e oitenta) dias, contados da data da publicação. Diário Oficial da União 2001; 16 mar.
23. Brasil. Resolução RDC n. 47, de 28 de março de 2001. Determina que os medicamentos genéricos registrados ou que vierem a ser registrados junto a Agência Nacional de Vigilância Sanitária, devem ter, para facilitar a sua distinção, em suas embalagens externas, o logotipo que identifica o medicamento genérico, de acordo com as instruções desta Resolução. Diário Oficial da União 2001; 30 mar.

24. Glatter J. Promotion, information and advertising: Why increasingly blurred boundaries do not benefit the public. Journal of Generic Medicines 2004; 1:128-37.

25. Oliete MB, Bouza CT, Bustillo BM, Cuesta TS, León MN. Opinion de los usuarios de atencion primaria sobre los medicamentos genericos y el coste de la medicacion. Aten Primaria 2003; 31:170-7.

26. Bruneton C, Favre I, Fontaine D, Maritoux J, Rey J-L. Concours pour la promotion des medicaments essentiels generiques en Afrique. Sante 1999; 9: 47-52.

27. Brasil. Resolução 133. Dispõe sobre o registro de Medicamentos Similares e dá outras providências. Diário Oficial da União 2003; 2 jun.

28. Agência Nacional de Vigilância Sanitária. Mercado de genéricos no Brasil. http://www.anvisa. gov.br (acessado em 04/Jun/2004).

29. Associação Brasileira das Indústrias de Medicamentos Genéricos. Informações de mercado. http: //www.progenericos.org.br (acessado em 09/Jun/ 2004).

30. World Health Organization. Comparative analysis of national drugs policies second workshop. http://www.who.int/medicines/library/dap/whodap-97-6/who-dap-97-6.pdf (acessado em 20/Jun/ 2002).

31. Associação Brasileira das Indústrias de Medicamentos Genéricos. História dos medicamentos genéricos. http://www.progenericos.org.br (acessado em 30/Dez/2002).

Recebido em 15/Dez/2004

Versão final reapresentada em 01/Set/2005

Aprovado em 24/Nov/2005 